\title{
SMART LEARNING ENVIRONMENTS IN A CONTEMPORARY MUSEUM: A CASE STUDY
}

\author{
ILONA TANDZEGOLSKIENE \\ Institute of Education Research, Vytautas Magnus University \\ Jonavos str. 66, Kaunas, Lithuania \\ E-mail address: ilona.tandzegolskiene@vdu.lt \\ ORCID: https://orcid.org/0000-0002-7734-5475 \\ JUDITA KASPERIUNIENE \\ Faculty of Informatics, Vytautas Magnus University \\ Vileikos str. 8, Kaunas, Lithuania \\ E-mail address: judita.kasperiuniene@vdu.lt \\ ORCID: https://orcid.org/0000-0001-6851-7637
}

\begin{abstract}
Aim. The modern museum becomes an attractive learning space where the visitor, depending on age and competence, develops personal experience and constructs the learning process based on individual goals. The article aims to reveal how spaces in museums are exploited and in what ways visitors are involved in a narrative that connects the present and the past.

Concept. The research uses a case-study method to investigate the POLIN Museum of the History of Polish Jews (Poland), Ruhr Museum (Germany), and Vienna Technical Museum (Austria). Within the smart learning environment context, this study explains how to encourage museum visitors to learn and seek answers.

Results and conclusion. Four main directions are emphasized: the construction of a narrative through the creation of spaces and places, the creation of a historical narrative through simulacra, the educational effect of smart solutions, and edutainment. The findings show that change in the museum by combining design solutions, historical narrative, time experience, and smart technologies leads to cognitive and engaging learning, touching, feeling, and experiencing different emotions, encouraging a return to the museum, inviting to learn, and shaping one's personal experience.

Cognitive value. Contemporary museums invite visitors to a new experience by combining artistic space design, storytelling, individual time management, and the use of smart learning environments. These challenges are shifting museum narratives and influencing non-formal learning programs. Authors raise a discussion of how, by exploiting museum spaces, the visitors are involved in the stories, and how the smart learning environment is created in a modern museum.

Key words: contemporary museum exhibitions, edutainment in a museum, museum narratives, smart museum learning environments, storytelling
\end{abstract}




\section{INTRODUCTION}

mart technology applications in education have been of interest for many years. SIn this article, we refer to Gwo-Jen Hwang (2014) who states that "a smart learning system can be perceived as a technology-enhanced learning system that is capable of advising learners to learn in the real-world with access to the digital world resources" (Hwang, 2014, p. 2). A smart learning environment (SLE) has the following characteristics: context-awareness, adaptive support to learners by immediate analyses of the needs of individual learners from different perspectives, and ability to adjust to the individual learning style and performance. Contemporary SLE can be defined as a learning environment in which artificial intelligence solutions are implemented and which uses emerging pedagogical approaches and techniques. SLE studies, so far, are controversial. According to some researchers, smart learning environments can provoke learners' non-engagement behavior, such as distraction, change of learning goals, being out of focus, laziness, and even cheating for the best result (Wong \& Chong, 2018). Meanwhile other scientists believe that SLE involves learners of all ages (e.g. Gao et al., 2019; Kiili, 2005) and facilitates flow experience (e.g. Heutte et al., 2016; Pranskuniene, 2013).

In analyzing how non-formal and informal learning takes place in a museum, Rasa Pranskuniene (2013) argues that museum education could be identified in a multi-layered manner: overall museum activities; as formal and non-formal learning center; multidisciplinary, continuing or lifelong learning spaces (Pranskuniene, 2013, p. 6). Museums are places of culture, education, and experience. The central concern of a museum has always been related to collecting, preserving, and studying its core assets, i.e. the collection of artifacts and extensive cultural knowledge associated with the artifacts (Tim, Ouyangb, \& Zengc, 2019). Museums are traditionally dedicated to visitor's relationship with the past. They collect the heritage of human culture and past experience, and hence aspire to enable a bridge between the past and the present. At the same time, the conception of a museum is open to different experiences in arts and science, and to different social values.

Nowadays the cascade of innovations in digital media has profoundly changed museum formats and characteristics. Contemporary museums provide space to interpret visible and hidden historical events and experiences (Badalotti, De Biase, \& Greenaway, 2011). However, talking about the mission of a contemporary museum, a new concept of a museum is emerging. This concept is associated with a clash of different cultures and the promotion of new ideas and projects, when scientific ideas, artistic perspectives, and learning innovations come together, focusing on movement through the museum spaces, from the beginning of a narrative towards its end, or moving to topic analysis and immersing in personalized cognition of objects. A contemporary museum establishes a connection with the visitor, maintains a dialogue, and exhibits using a concept that is associated with innovative artistic solutions, aesthetics, feelings, and experience. This suggests that the connection with the visitor is being established continuously. This means an invitation to get involved in the life of the 
museum and to feel its expositions through experience and emotions. Visitors are attracted by experience, which can be achieved based on the museum exhibits and the "here and now" strong emotions experiences that lead to learning and cognition. The visitors are also attracted by the museum's ability to tell stories that encourage empathy for the time, character, or to experience a feeling of sublime. Local authenticity or event knowledge strengthens the assimilation of new experience. Apart from that, various innovations are used, such as 3D images, digital photos, audio guides, music, and installations. For example, in the collection "A Guided Tour through the Museum of Communism" researched by Jakov Sabljić and Tina Varga Oswald (2013), visitors are attracted through a narrative, complex and sensitive stories are told using metaphors and folk tales, and the moral of the narrative. This type of a museum narrative may have obvious overlaps and substantial deviations from the classical content and form of the fable. All these measures help the visitor to search for answers individually, to read, explore, listen, and walk around the restored authentic places. The opportunity to create a story and experience it in its way, as well as the opportunity to participate in the development of individual learning and cognition, appear next to emotion, experience, and knowledge. The visitor becomes interested in smart technologies, which, in turn, transform the visitor from a passive participant into an active co-creator. Different visitor groups (e.g. pre-school age children, pupils, adults, elderly people) also pose some challenges for the museum as the content and transmission of content must be prepared for different age groups by adapting to the learning abilities of target groups and considering socio-cultural needs (Dierking \& Falk, 2005).

Today, with the help of smart technologies, a museum can create exhibition spaces that go beyond geographical boundaries and physical constraints (Tim, Ouyangb, \& Zengc, 2019). For example, digital surrogates of extremely high precision can be created and made widely available, for even the most exclusive of cultural artifacts. With the support of mobile devices and social platforms, museum audiences are also given a more powerful role in shaping the cultural experience that museums have to offer.

The main questions of this research are as follows: how, by exploiting museum spaces, the visitors are involved in the stories of the past and the present, which are narrated with the help of artifacts; and how the smart learning environment is created in a museum. To answer these questions, three museums are analyzed, i.e. POLIN Museum of the History of Polish Jews (Poland), Ruhr Museum (Germany), and Vienna Technical Museum (Austria).

\section{RATIONALE}

The interplay between technology and non-formal education

Smart technologies allow the creation of information services of museums with a new format and combining them with descriptions of museum exhibits, various texts, or old photographs. Dmitry Korzun et al. (2017) suggest 
the following directions of smart museum services: layered functionality, multisource information, and human involvement. These researchers compare a modern museum to a semantic web of meaningful fragments of information. Such a semantic web connects humans (museum staff and visitors) and interactive technologies (physical expositions or museum artifacts). In this web, the museum expositions have become not just a large database - in which information is used traditionally in a passive way when the visitors walk around the museum spaces and observe static artifacts - but also an active center for knowledge creation. Seeing which exhibition spaces are most visited, which parts of the exhibition are the most attractive to the visitor, the museum staff can adapt the exhibition to different groups of visitors and individualize it according to the needs. The museum services are expanded because the use of smart devices, such as mobile access, allows expanding and layering the exhibition (i.e. interacting not only with the visitors and professionals, but also with smart objects), presenting additional museum artifacts, or individualizing the story which is being told, while considering the initial knowledge of the visitors. The use of smart technologies enables the active contact with museum exhibits and obtaining additional information. In this way, a museum becomes a center of non-formal learning.

Augmented and virtual reality in museum expositions has a big impact on the visitors' experience and satisfaction. These technologies allow museum expositions to be individualized depending on the content of the exposition, presentation of the exposition, the functionality of the exhibits, interaction with the museum exhibits (the possibility to touch, change, and create the exhibit), pragmatic and hedonic attributes (audio or visual aid, elements of gamification). Virtual and augmented reality in the museum expositions flexibly adapts to the visitor's profile, the time spent by the visitor (how much time does the visitor have for viewing the museum expositions), comments from other visitors who have previously visited the museum, and other conditions (Trunfio \& Campana, 2020). The possibility of the museum exhibits to transform, depending on the wishes of the visitor, makes the expositions more captivating, attractive, and understandable. Consequently, the visitor is motivated to return and to get deep into the stories narrated by the exhibits.

\section{LIVE AND FROZEN TIME IN MUSEUM EDUCATIONAL NARRATIVES}

For many museums, the timeline of the visitors, based on which the expositions are presented, seems like a natural way to experience and understand the past. Two methods of time representation - Chronos and Kairos - are distinguished in analyzing the construction of personalized experience in works of art, literature, cinematography, and museum expositions.

Chronos refers to time which is measured as a sequence or order. It is chronologically similar to the clock display time (Hannam \& Ryan, 2019). Chronos 
means a quantitative experience of time. It is the perception and representation of the duration, object, event of the narrative of the time as the time of history, or of the age of the person (Metcalfe, 2006). An exposition consisting of articulation of time that is presented consistently and this is presented as a historical chronological sequence of events, as a homogeneous, orderly, and seemingly objective flow of time. In modern understanding, time as Chronos is presented as a linear experience - i.e. as a linear time with a sense of historical continuity (Hom, 2018). Kairos refers to specific fateful and life-changing moments and turns of time, it is a critical time or time that is "appropriate" to act, a time that is presented as a great opportunity to get to know and understand (Hannam \& Ryan, 2019). Thus, the concept of Kairos emphasizes the opportunity and possibility to take advantage of this moment to take appropriate steps and is considered to be of higher quality in terms of learning and emotional experience. In some texts, the concept of Kairos emphasizes the importance of the experiences, interpretations, understanding, and narratives of the subjects, on their life path or in a historical sequence of events. The temporality of Kairos reveals existential feelings and transformations, which not only interrupt the Chronos flow of time but at the same time are associated with transformations in space (in some cases in the post-apocalyptic space), which is temporarily decoupled from historical time (Chronos).

Timelines are useful and very effective, but should be used carefully as narratives. The timeline speaks about assumptions of narrative structure, about past, about chronological or not chronological understanding, and about progress. It makes it seem as though history is a path to the present. More to the point, it hides those assumptions remarkably well. So, innovative technologies that are sending open or hidden messages to combine and enhance the learning experience and aesthetic experience, play a big role next to the timeline and the story being created (Lubar, 2013). According to Lubar (2013), the presentation method used in Chronos restrains emotions, invites the visitor to follow the story from beginning to end, but does not create a place in the space of storytelling for additional questions or experiences to understand specific or desired events in the course of the process. Kairos, meanwhile, allows the narrative to masterfully penetrate the sequence of events and turns the information presented into a narrative by paying attention to current issues, important events, etc. In this case, the story is told in a new way each time, depending on the person's involvement and motivation. It is also important to mention that a narrative told by another person is a powerful weapon, an ideological instrument, and this may create tremendous emotional energy, which is directed towards positive and/or negative learning experience. Thus, moving the existing artifacts into a new discourse can be organized based on five ways of transmitting information: by location, by categories (topics), by time, in alphabetical order and in hierarchical order. As Lubar (2013) observes, the tendency that a chronologically and consistently organized sequence of exhibition presentation is a logical solution has prevailed for a long time. This was especially 
obvious in art and history museums, where it has been argued that people live according to the flow of time. So, for a historical period to be restored, it must also be organized according to time. In this case, good stories, which are visible and may arouse interest and involvement, are important for the creators of history - for the employees of museums. When the visitor moves in the Chronos way, it is somewhat stated that there will be no alternatives because this timeline has no other "paths" to choose from. Consequently, if a decision is made to stay in Chrono's linear presentation of history, the past seems obvious. It is presented the same to everyone, as if it was impersonal and homogeneous. In the sense of learning, such a presence in linear time can help visitors to understand the sequence of events and to find out what led to them. However, speaking from the perspective of everyone's life experience, we "do not walk through time", and we cannot experiment and try to see what will happen next. Each of us sees a different flow of time, and we experience certain events differently. It is more about reflections, certain interfaces between objects, grouping of experiences, construction of details, and information as a whole. It is more similar to Kairo's time, where heroes live and work, and the visitor of the museum stops and experiences feelings. The narrative technique at storyline to dissemination, in particular for historical and cultural contexts, can enrich learning through the emotional impact, and its importance likely to get ever higher, because of at least two factors (Palombini, 2017; Barclay, 2020):

- the story can be told according to the principle of traditional storytelling, where events are associated with historical data and it is fairly simple to predict that the visitor has acquired a certain structure of knowledge and thoughts in advance, and this does not help the visitor to learn;

- the second version of the narrative is related to the nature of the narrative itself, which encourages us to question, stop, explore, and immerse in the storyline. The interest in the story is even greater if the story has strong links to the location and is associated with an emotional attachment to the location.

Again, the complexity of the narrative, as a creative product, has to be remembered because the narrative is created based on scientific information and human experience. A questioning approach, that is more philosophical, specifically "How to combine scientific information and the artistic freedom of the narrator using innovative/smart technologies?", "How does this affect the visitor?", "What emotions and new experiences arise from storytelling when focusing on the experiences of the characters and the emerging real scenes?", becomes stronger here. It can be noticed that there are no very clear and precise structures for the plot of the narrative. However, a few rules are called for observance: nothing that contradicts historical documents can be told, the narrative itself can be focused on both the character and the place of action. It is also important to note that the narrative can be aimed at presenting famous people and facts, which are related to the objects of the exposition, and in this way, historical events of the world are explained, artistic or scientific information is pre- 
sented. The main arena feature is that in the plot general structure, important (real, documented, generally famous) people and facts are the main elements and characters, as ordinary (trivial, undocumented, and then fictional) people and facts are used as background. In another case, it is still possible to focus on the presentation of daily life, where the narration is focused on everyday life dimension and the protagonists are ordinary (fictional) people, whose actions illustrate historical processes seen "from below the official history", even in the absence of documented (real) events or characters (thus, communicating what history books will never be able to tell). The main arena feature is that in the plot general structure, ordinary (trivial, undocumented then fictional) people and facts are the main elements and characters, as important (real, documented, generally famous) people and facts are used as background (Palombini, 2017). Thus, in the first case, the focus is on interpretation and narration through known historical events or people, and in the second case, the focus is on emotional experiences and presentation of history, based on access to daily life.

It is important to analyze how and by what means the aesthetic sense is created in the museum and the visitor is helped to get to know the exhibits and objects presented. As already noted, a museum is more than a space that preserves objects of heritage and important artifacts. However, it is also a space where learning takes place and where a new authentic experience is constructed. This is influenced by architectural and artistic solutions, the use of innovative technologies, and ways of presenting the plot. In discussing the possibilities of learning and experience construction when visiting a museum, it is relevant to talk about an identity presented by the museum, technological solutions, and strategies for conveying the storyline.

\section{METHODOLOGY}

The case study was developed (Yin, 2009; Baxter \& Jack, 2008). The research focuses on the description of objects and museum exhibits and the presentation of smart technological solutions. The empirical research examines how personalized learning is developed in a museum and how the authentic experience of the visitors is constructed. Three museums in the European countries, specifically, the POLIN Museum of the History of Polish Jews (Poland), Ruhr Museum (Germany), and Vienna Technical Museum (Austria), were selected for the empirical analysis. The museums were visited in 2018-2019. During the case study, it is important to focus on learning events that inspire the construction of new experience, emotional experience, and authentic presence in the museum spaces. During the analysis of the museum spaces, each space was described and information was captured with a camera. The spaces were described by specific thematic fields: authenticity of location, presentation of exhibits, innovative and entertainment solutions, and the feelings that the visitor experiences. 


\section{FINDINGS}

During this research, three museums were visited. Detailed information is presented in Table 1.

Table 1

Basic information about museum cases

\begin{tabular}{|l|l|l|l|l|l|l|}
\hline No & $\begin{array}{l}\text { Museum } \\
\text { code }\end{array}$ & Name & $\begin{array}{l}\text { Country, } \\
\text { city }\end{array}$ & $\begin{array}{l}\text { Date of ob- } \\
\text { servation }\end{array}$ & $\begin{array}{l}\text { Essential } \\
\text { information } \\
\text { about the } \\
\text { museum }\end{array}$ & $\begin{array}{l}\text { Online link to } \\
\text { the museum }\end{array}$ \\
\hline 1. & M1 & $\begin{array}{l}\text { POLIN } \\
\text { Museum of } \\
\text { the History } \\
\text { of Polish } \\
\text { Jews }\end{array}$ & $\begin{array}{l}\text { Warsaw, } \\
\text { Poland }\end{array}$ & 29-03-2018 & $\begin{array}{l}\text { Museum of } \\
\text { the History } \\
\text { of Polish } \\
\text { Jews }\end{array}$ & $\begin{array}{l}\text { https://www. } \\
\text { polin.pl }\end{array}$ \\
\hline 2. & M2 & $\begin{array}{l}\text { Ruhr Mu- } \\
\text { seum }\end{array}$ & $\begin{array}{l}\text { Essen, } \\
\text { Germany }\end{array}$ & $31-01-2019$ & $\begin{array}{l}\text { Local histo- } \\
\text { ry museum }\end{array}$ & $\begin{array}{l}\text { https://www. } \\
\text { ruhrmuseum. } \\
\text { de/startseite/ }\end{array}$ \\
\hline 3. & M3 & $\begin{array}{l}\text { Vienna } \\
\text { Technical } \\
\text { Museum }\end{array}$ & $\begin{array}{l}\text { Vienna, } \\
\text { Austria }\end{array}$ & 07-05-2018 & $\begin{array}{l}\text { Technical } \\
\text { museum }\end{array}$ & $\begin{array}{l}\text { https://www. } \\
\text { technisches- } \\
\text { museum.at/ }\end{array}$ \\
\hline
\end{tabular}

Source: own research.

It took 20 years to develop M1 (1993-2014). The museum, as a final result, has appeared thanks to a public-private partnership. While in this case, Jewish Association, Ministry of Culture and National Heritage (Poland) and the private sector joined their forces and efforts. Barbara Kirshenblatt-Gimblett (2015) notes that subject to the agreement, the public sector partners were responsible for the construction of the building, while the private sector was responsible for product development. "Event Communication", a professional company from London, helped to develop the products. The company worked with a group of historians from 2000 to 2004. Rainer Mahlmäki, the architect of the building, created a transparent, open space for reflection with many large windows, which let in sunlight, reflect clouds, and create ever-changing images and moods in the building itself.

M2 was opened in 1918 and is considered one of the oldest technology museums in the world. A building of classical architecture, that was specially designed for the museum in 1909-1918 by an architect Hans Schneider, is located in Vienna Penzing district, at 212 Mariahilfer street. In 1992-1999, the museum was reconstructed, its authentic exterior and interior were preserved, and the concept and design of the expositions were renewed.

Essen, where M3 is located, has been known since the 19th century for its iron mines and industrial buildings, which occupied an area of 35 hectares. Although this period of industry and industrialization is already a thing of the past, this city is still being shaped by industrial heritage. The closed mines and factories make the city unique, and the history that is being told attracts visitors. 
In 2010, M3 - which was established in 1904 as a museum of nature, history, and art - was moved to a transformed coal mine and coal wash building. The authors of the transformation were the Office for Metropolitan Architecture, Heinrich Boll, and Hans Krabel.

The next sections will discuss the smart learning environment in these museums.

\section{Construction of museum narratives in specially designed spaces}

Museum narratives can be constructed in various ways: by telling stories, enhancing the emotional impression with the help of the exterior and interior spaces of a museum, creating museum narratives together with the visitor, motivating to create personalized stories.

M1 museum is focused on the concept of creating storytelling. When the visitor passes into the museum, he/she enters a gallery of seven stories, the so-called "history theatre", with a prologue, an epilogue, and picturesque storytelling. There are not many original objects in the museum. However, M1 follows the principle that creating a story based on objects as a basis would complicate consistent storytelling when moving from one story to another. The idea of contemporary art and performance that is being developed at the M1, seeks emotional resonance through the presentation of authentic stories. The idea of Gesamtkunstwerk, which is identified as a co-creation of art through elements, by linking them into a single whole, is also followed here (Kirshenblatt-Gimblett, 2015). The visitors can choose here how much time to spend in the museum and how to spend it, i.e. they can choose a guided tour, a recorded guide or a printed guide. This museum creates a safe space for the visitors for critical reflections, discussions, or new plugins of tolerance (see Figure 1).

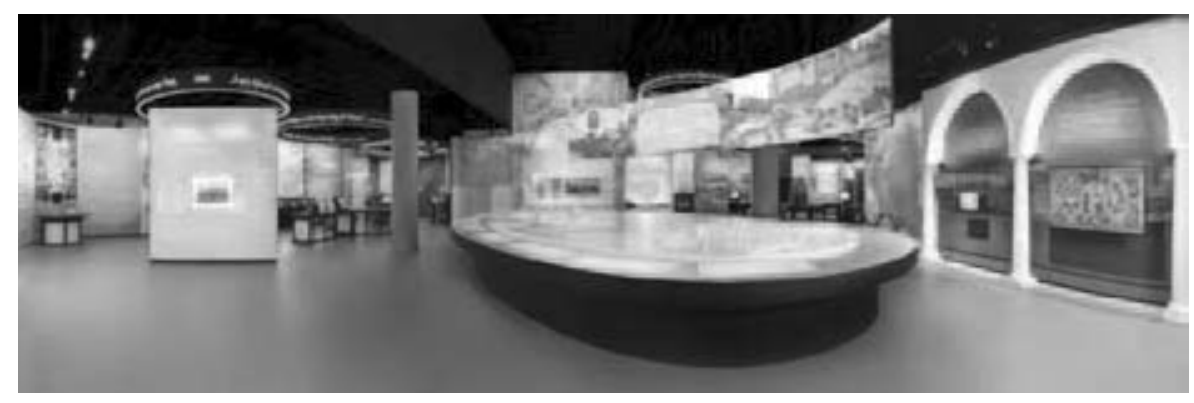

Fig. 1. The authenticity of POLIN Museum spaces

Source: own research.

M2 expositions are presented by the thematic field - "Present," "Memory," and "History." These topics are in turn divided into more detailed narratives. "Present" presents myths and stereotypes about the region through topics such as work, solidarity, or homeland. In the "Phenomena" units, the visitors can get acquainted with the ethnic and linguistic composition of the population of the region, hobbies, pets, fine architecture (kiosks), leisure, culture, "industrial" 
nature, as well as the sounds and smells that are characteristic of this region. The narrative of the exhibition is complemented by a personalized way of presenting history - three "heroes" are asked to tell about the things they value in this region. The second part of "Present" is called the "Signs of Time." In this part, natural objects (fossils, minerals) and "biographical objects" are exhibited side by side - things brought by people through which some special story is told. It is a map of modern collective memory. The "Memory" exposition tells the geological, biological, archaeological, and cultural history of the region, from ancient times to the present day. Historical periods (Bronze Age, Stone Age, etc.), cultural movements (Reformation, Enlightenment, etc.), various geological, archaeological, and cultural collections are presented here. The "History" exposition presents the history of industrialization in the region from the 19th century to the present day. This narrative is constructed according to dramaturgical principles: prologue (history of the geological strata of the region), beginning (1750-1830), minerals, technical innovations (1830-1870), rise (politics and business 18701914), urbanization (1914-1957), transformations (1957-2010). Temporary exhibitions are also held alongside the permanent exposition of the museum. The museum also offers tours called the "Coal Road." During them, together with a guide, the visitors can visit the coal processing plant and follow the path of coal extraction and processing in the industrial building, which was preserved in its original form when it was left by the last workers in 1986. The thematic units of the museum exposition correspond to the objective that is set in the mission of the museum - to become a place of memory of the region as it covers the whole history of the region (see Figure 2).
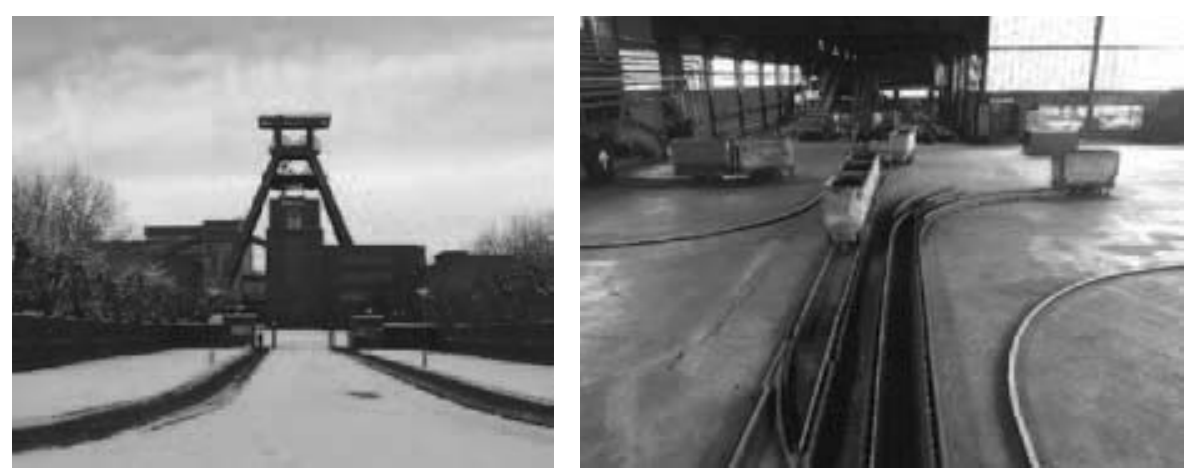

Fig. 2. Visual presentation of M2 museum

Source: own research.

A traditional exhibition of authentic artifacts, supplemented by interactive facilities, elements of science demonstration shows, and other modern elements of scientific and technical education, is the key innovation of M3. A narrative based on the principle of traditional thematic classification of science (Physics, Chemistry, Biology, etc.) has also been abandoned in the exposition. According to Peter Donhauser, the then director of the museum, these changes 
were a novelty among the European museums, and they have inspired many institutions to change (Peter Donhauser, Science vs technology in a museum's display: changes in the Vienna Museum of Technology with a focus on permanent and temporary exhibitions and new forms of science education / / Science Museum Group Journal, Autumn 2017, Issue 08) (see Figure 3).
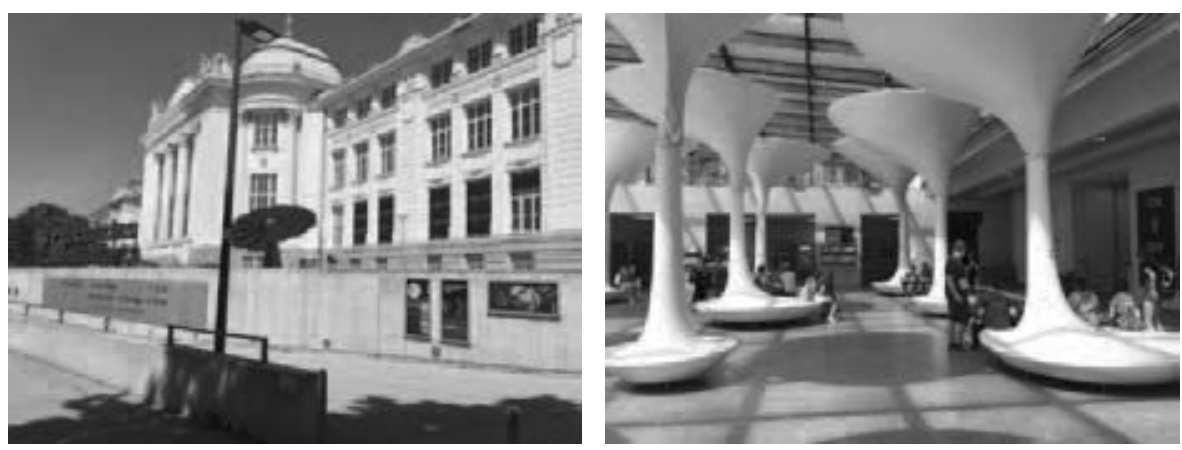

Fig. 3. Spaces of M3 museum

Source: own research.

These examples show that museums are changing the concept of displaying museum exhibits to attract visitors.

\section{Construction of a historical narrative using simulacra}

There is a surprisingly little number of authentic artifacts in M1. In most cases, museum artifacts are created employing art and new technologies, which are valuable in terms of their content, but not in an authentic material form. There are not many material artifacts of historical-museum value; musical instruments, individual parts of clothing, candles are rather rare elements of the exhibition. The materially authentic exhibits are incorporated and combined with the exhibits created in an artistic-technological way, and these are integral elements of the overall narrative. Stories are attempted to be told based on the experiences of different characters and by presenting their characters. The exposition presents the lives and stories of individual people, which are incorporated in a particular historical event and period.

The uniqueness of M2 lies in the fact that it presents not only the history of industrialization but also the natural and cultural history of the whole region from the geological period to the present day. In 2001, the World Heritage site Zollverein Coal Mine Industrial Complex was listed on the UNESCO list of protected areas. In this way, M2 appeared in the coal wash building, the "Red Dot" Design Centre - in the boiler room and in the casino in the building of low-pressure compressors. The World Heritage site Zollverein Coal Mine Industrial Complex coal mine complex also has spaces for artists, local traders, ice arena, swimming pool, conference hall, and a restaurant complex. The main focus here is on the activities of the museum which are very diverse and dedicated to getting to know the whole region and preservation of the memory. 
The concept of the museum that focuses on aesthetics and the presentation of culture and education is being developed nearby based on various tools (photography, showing of short films, artifacts, virtual maps, installations, visualizations).

To sum up, a museum can be created not only from authentic artifacts but also by using copies of exhibits, artificial models, unnaturally expanded spaces, imaginary and inauthentic environments.

Smart technological solutions for museums

The part of the exposition of M1, which presents the 19th century, is dominated by dark colors (technological artifacts of this time, i.e. photos, are used). This black and white visual material is playfully incorporated by simulating the technique of three-dimensional pop-up books for children in some places (three-dimensional books for children are created from several photo patterns). The presentation of material from the 20th century is more dominated by technologies that are applied in this century (black and white photos, the material of documentary black and white films); various visual effects are used to enhance the impression, which focuses attention and facilitates the perception of rich visual (image and text) information, tone or highlight a black and white color. For example, several black and white photos are presented by placing them in a separate visual format, which breaks down the image into individual forms-figures and using colored lighting (Figure 4).
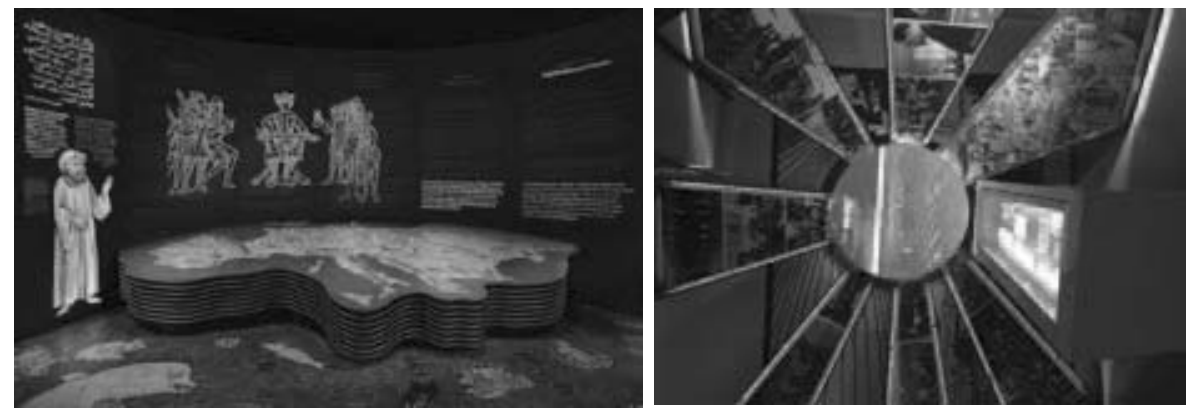

Fig. 4. Innovative solutions for storytelling Source: own research.

An interactive table - on which photos of individual families and people or documents describing events are placed - is one of the most interesting exhibits in M1. The visitors can move the photos on the table by hand (e.g. select a photo, zoom it in, or zoom it out). Once the photo is selected and touched, a short text on the content of the photo opens up, describing what is depicted in the photo, the circumstances in which the photo has appeared, the depicted event, the comment of the photo owner (see Figure 5). An interactive mailbox is another interesting technology that is used to present the stories of the participants. The letters presented are from immigrants who wrote them to their family members but they were not sent for censorship and never reached the 
family members. Those letters are like evidence of dramas that families had to experience.
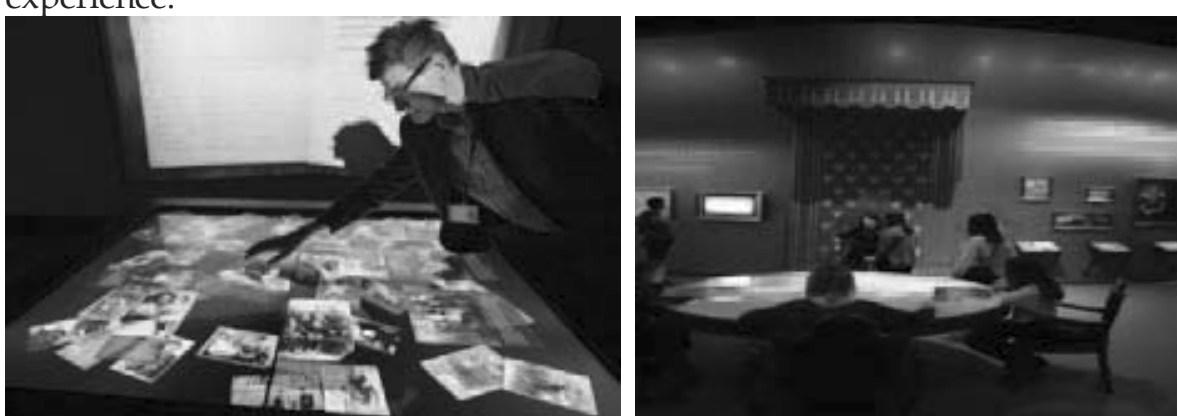

Fig. 5. Interactive board with personal photos and a presentation of the "red corridor" story Source: own research.

The presentation of World War I in M1 is again presented through slightly different technical solutions. This is strongly portrayed throughout a film, which is also linked to a relief map, and marks the collapse of the former empire, and the restoration of the Second Republic of Poland. This formation and growth of the Republic are presented with the aid of a street visualization (1918-1939). The two-story themed space covers two floors and is divided into four themes: culture and politics at the first level, and growth and everyday life at the second level. People looking up can be seen when the visitor approaches the end of the interwar street. This symbolizes the moment of World War II (see Figure 6).
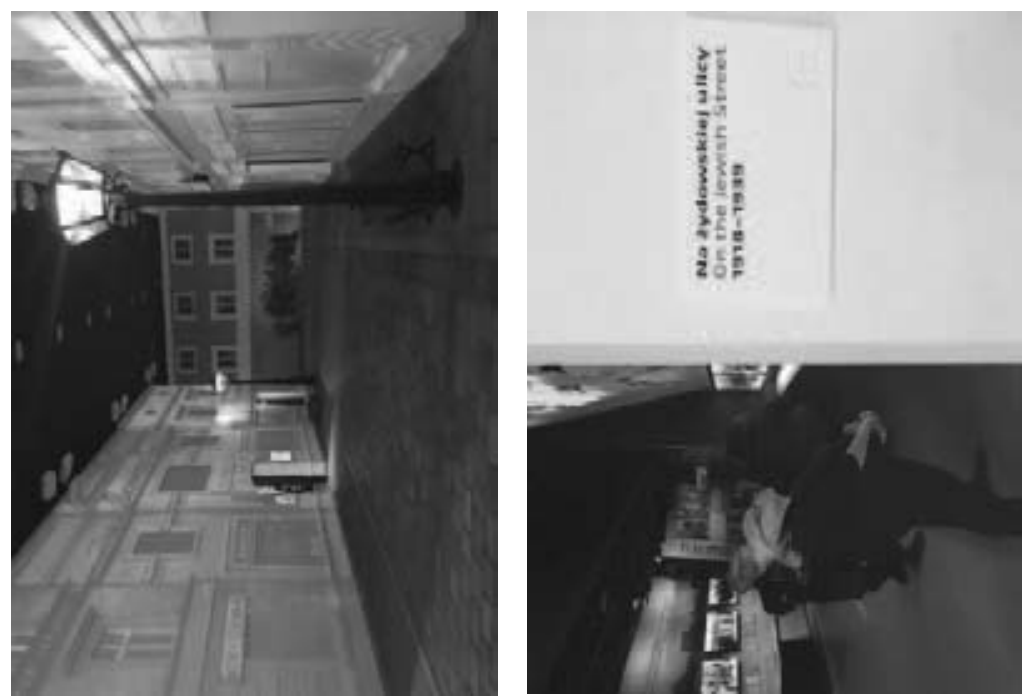

Fig. 6. Authentic restoration of streets Source: own research. 
The visual technologies used are very diverse in terms of forms and content (vertical, horizontal, interactive, or showing images that have been filmed or consist of photographs). However, each interactive screen provides endless choices. Therefore, it would probably take a few days to touch all the exhibits and read the information they contain, which is conceptualized both by the scientists who have contributed to the creation of M1 and design of the expositions and by IT professionals. The theme of the Holocaust and the history of anti-Semitism is analyzed in the museum in three time periods: before, during, and after the Holocaust. The organizers of the M1 idea and the members of the implementation group emphasize that the main idea of the museum is the presentation of a unique case - the history of Polish Jewish Life in Poland, by focusing on the community growth, prosperity, and changes, and on the narrative of transformation, noting that Polish Jews were a part of Polish society. Here, based on the M1 concept, it can be seen how a painful historical fact can be used not for the development of the story itself and the publication of painful moments, but as a constructive engagement in a fact-based trust-based narrative focused on creating a new culture that supports an ideology of inspiration and tolerance. After all, the concept of a conflict is not developed here, and it is repeatedly reaffirmed that Polish Jews are an integral part of Polish history (see Figure 7).
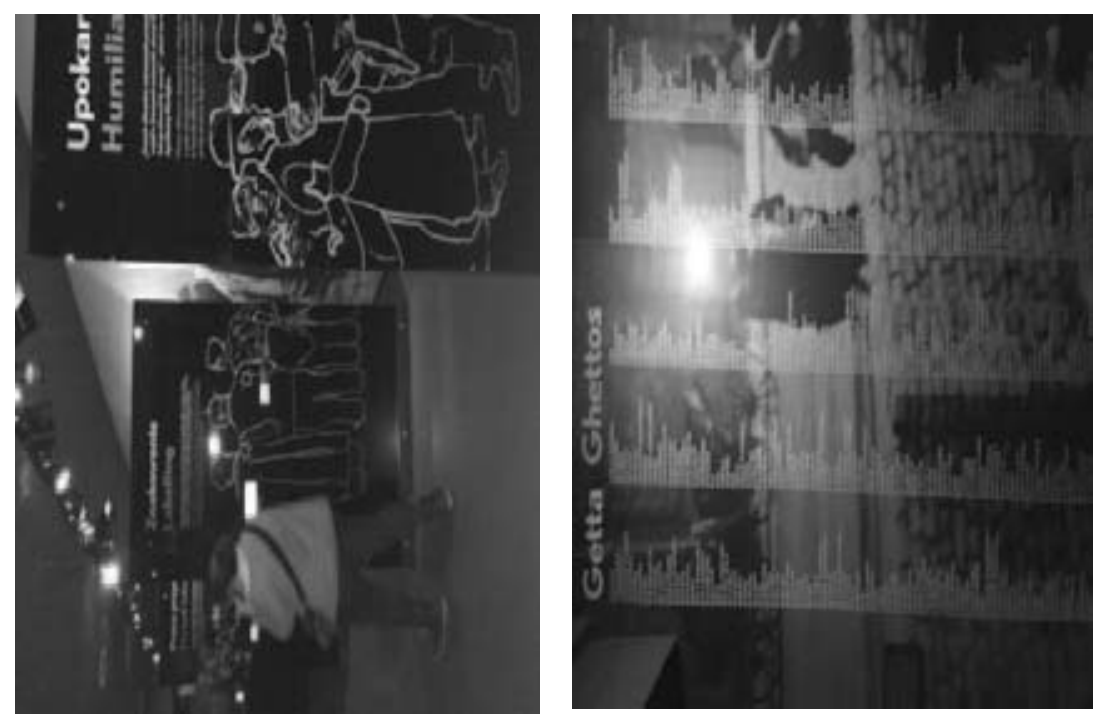

Fig. 7. Presentation of the Holocaust theme Source: own research.

The combination of photographs (less or more illuminated), notes, and screens with documentary materials (collages and multimodality) is typical of the exposition of the 20th century. It is important to note that 1-2 gaze focuses are distinguished in a common collage of photos and images, i.e. several 
photos and/or screens with video material, which are illuminated with brighter light in the background of still images (photos) and texts, are distinguished among several photos and images. The collages of photos and texts are not chaotic - certain points of gaze attraction are highlighted (1-2 glowing photos, screens). Multiple images on one wall (many photos) and image multimodality create the impression of the intensity ("thickness") of historical events, and reveal the 20th-century phenomenon of a mass era - mass movements, mass repressions, and mass crimes. The exposition is installed on one wall, where the visitor sees the profiles (photos, names) of several narrators on the screen and a handset for listening is connected to each narrator's profile. This way the visitor can choose the narrator by lifting the corresponding handset located by a narrator's profile. This is another impressive narrative of ordinary people that are presented with the aid of innovative technologies. At the same time, on the common board, next to the profiles (photos) of all narrators, there are questions that the visitor can click on and in this way choose a question of interest. The questions are designed to reveal the Jewish experience in present-day Poland: "What does it mean to be a Jew in present-day Poland?" “Does anti-Semitism exist in present-day Poland?" etc. After having selected the question, the visitor can also select the narrator by picking up the handset next to the photo and surname of the respective narrator. It can be assumed that during the process of compiling this exposition (data collection) all narrators were asked the same questions. Therefore, all the narrators of this exhibit answer the same questions.

In the M2 exposition, learning and entertainment are combined. The exposition presents a variety of exhibits: authentic artifacts (industrial facilities, biological, geological, cultural objects that have survived into present-day), works of art, photographs, narratives, video materials, explanatory texts, sound and odor installations, and information terminals. The exhibits in the collections of the museum are presented together with "biographical objects" telling everyday history, natural and cultural history, historical facts, and personal stories of people (see Figure 8).
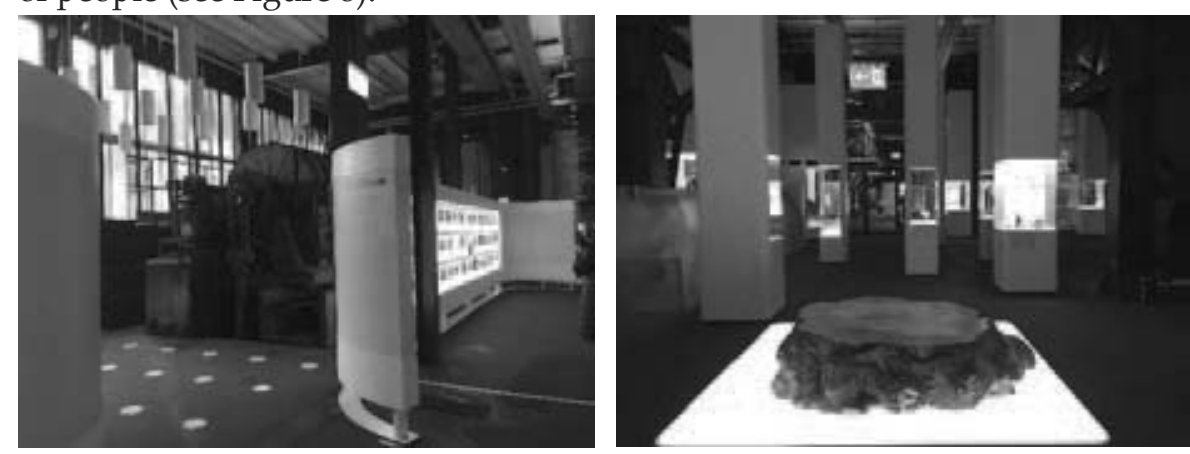

Fig. 8. Smart solutions at M2 museum Source: own research. 
The mission of the M3 museum is described as follows: "Here technology is an experience." However, a broader explanation of the mission emphasizes the connection between telling the history of technology and experiential knowledge of technology: "Historical exhibits, many of them unique, are showcased in their cultural context, with fun ways and methods of transferring knowledge making it possible to get to grips with technology." The visitors are invited to discover, experience, reflect, get to know, and discuss the mission of science and technology modernization in the museum. It can be concluded that the museum aims to present the history of technology, to promote experiential learning and experimentation, and to provoke critical discussion. To present the history of technology, the exposition focuses on the display of historical, authentic artifacts and on telling the history of one or another phenomenon (industry, energy, household appliances, etc.). To promote experiential learning, some parts of the exposition consist solely of interactive hands-on devices; in other expositions, authentic artifacts are accompanied by explanatory texts, models, films, works of art, photographs, documentaries, interactive devices, and games. To provoke critical discussion, the museum links technical objects to the political, economic and social context of their occurrence and use, seeks to bring scientific and technological phenomena closer to everyday life experiences, presents several angles of approach to the same phenomenon, and takes a clear position on polemical phenomena. Other units of the exhibition "Energy" present a variety of exhibits: authentic artifacts (from kerosene lamps to boilers, steam engines, and water turbines from old times), works of art, models of buildings, equipment, events (parts of the models are made of Lego blocks), explanatory texts, documentaries, and cartoons (for example, short videos demonstrating the operation of the machine tool are shown in the division "Industrial society"). Each unit also exhibits an interactive hands-on device, which enables gaining live experience; for example, the action of muscle strength or the action of the centrifuge principle. The M3 exhibition is dominated by interactive devices. In the black box, which stands at the beginning of the exhibition, the visitors themselves can test the examples of electricity generation - both used and experimental, utopian. The
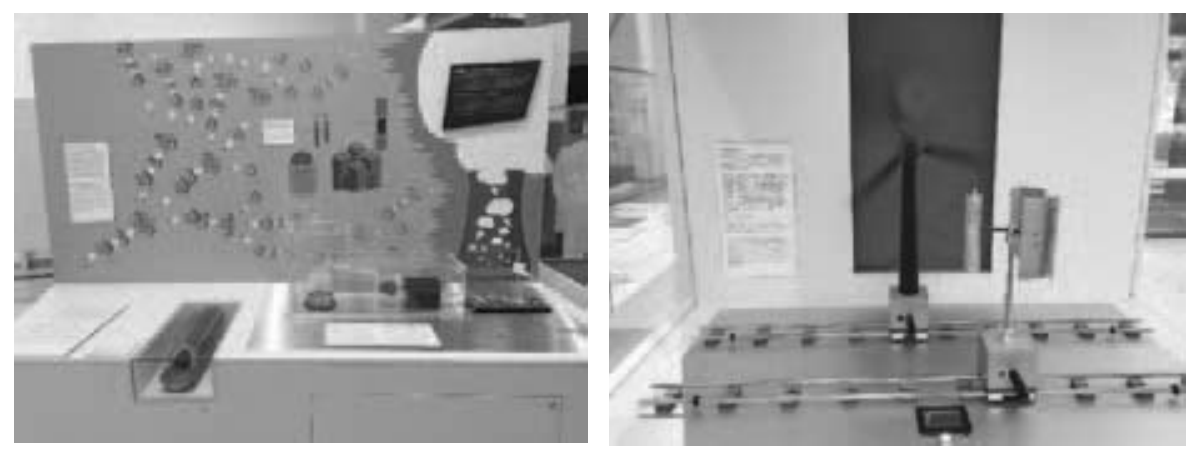

Fig. 9. Simulation exhibits at M3

Source: own research. 
interactive models allow visitors to get acquainted with the operation of BWR nuclear power plants, hydroelectric power plants, wind turbines, etc. A simulation electrical network control panel operates in the center of the exposition. The panel can be used to regulate energy flows in the exhibition space (see Figure 9).

Alongside the interactive hands-on devices, authentic, historical artifacts (from radio to the transformer station), information stands with photographs, large visualizations, and explanatory texts, documentaries, various documents, and archival material are exhibited in M3. The exposition also uses a personalized way of storytelling and spoken story. For example, personal memories of people are used while presenting the problem of what happens in the event of power supply failure. In summary, it can be argued that M3 successfully combines learning and entertainment aspects in its expositions. The narrative lines of the exposition combine both a historical, linear narrative of the evolution of technology in human life and a problematic thematic narrative covering both the phenomena themselves (e.g. energy) and their functions in everyday life, as well as the political, economic and social problems associated with the phenomenon. There is a great variety of exhibits in the exposition: from automatically attractive authentic, historical artifacts (e.g. they can be admired as examples of technological design) to abundant explanatory and illustrative material (textual, visual, and audio-visual), games, and interactive devices designed for operation and experience. There is a good balance across various exhibits. The exposition "Energy," which was installed earlier, is dominated by authentic, historical objects and models, while the newer exposition "ON/OFF" is dominated by interactive devices and information stands. Both exhibitions, however, meaningfully complement each other. A special atmosphere is also created in the exposition (authentic environment and objects) and narrative elements are used as a personalized way of storytelling (spoken story).

\section{Edutainment in museum}

Edutainment in M1 is seen as a sensory experience of the visitor, who is invited not only to observe and read but also to hear sounds and touch and objects. The audio guide of M1 presents individual historical stories and narratives that summarize the visual information presented in the halls. The audio guide information is therefore essential as it attached meaning to the exhibits in the halls. The exhibits and inscriptions present only individual elements (often with original quotations of historical figures from documents or works). The idea of the whole hall (part of the exposition) can be fully understood and decoded only after hearing the summaries presented by the audio guide. The exhibits themselves only illustrate and expand the essential information presented by the audio guide. Each hall has its sounds. If a city with its inhabitants is depicted, then sounds of birds and the bustle of people can be heard. Quiet Jewish music is played in the hall of Jewish cities. There was a gramophone in one hall, music was played, and the room invited the visitor to try to move following the music (see Figure 10): 
At least one interactive screen - that visitors can touch and select content from - is available in nearly every M1 hall. Individual exhibits are designed to be touched: in the hall called "Town" the visitors can touch a wooden goose of natural size (its wing can be lifted to see a written text under the wing), a wooden-metal fish can be touched and opened to read the text about the fish. There are also several wooden/ metal pieces of garlic bearing engraved texts hanging nearby. M1 offers educational interactive activities related to touching. One of the involves making a historical coin with its name written in Jewish and bearing other decorations. It takes about 5 minutes to make an old coin and this process engages in an interactive educational activity that involves recognizing letters written in Jewish and adapting them in making their nominal coin (see Figure 11).

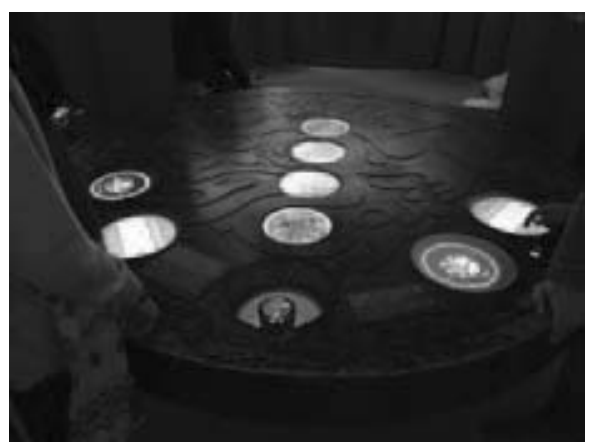

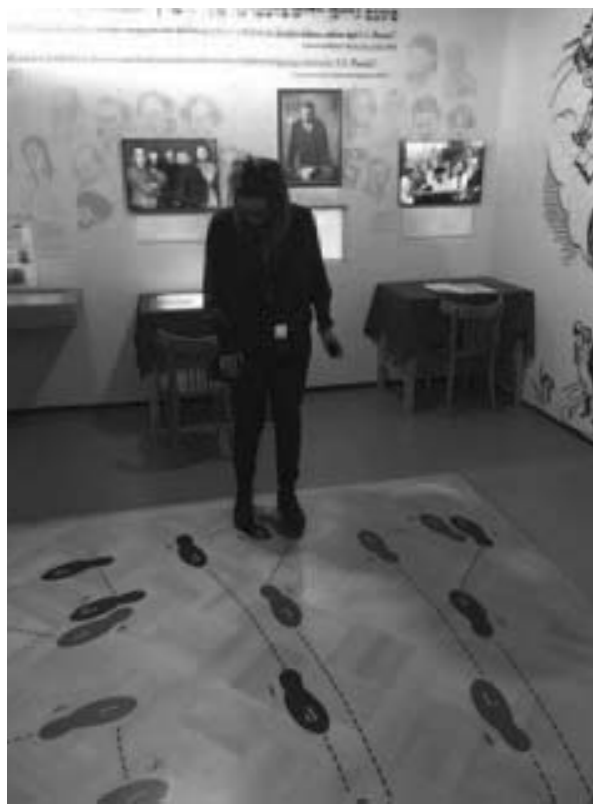

Fig. 10. Musical hall at M1.

Source: own research.

Fig. 11. The process of a "personal coin" creation at M1

Source: own research.

M2 exposition combines learning and entertainment (edutainment). The exposition presents a variety of exhibits: authentic artifacts (industrial facilities, biological, geological, and cultural objects that have survived into present-day), works of art, photographs, stories, video materials, explanatory texts, sound and odor installations, information terminals. The important thing is that the exhibits of the museum collections are presented together 
with the "biographical objects" telling the history of everyday life, thus forming a combination of natural and cultural history, historical facts, and personal stories of people. The narrative lines of the museum exposition do not emphasize the history of the development of industrialization, but rather link it to the natural, economic, social, and cultural process of the region. The exhibition presents industrialization through its impact on nature and human life. The exhibition links the processes of industrialization to the daily experiences of the visitors through biographical narratives and everyday stories (see Figure 12).
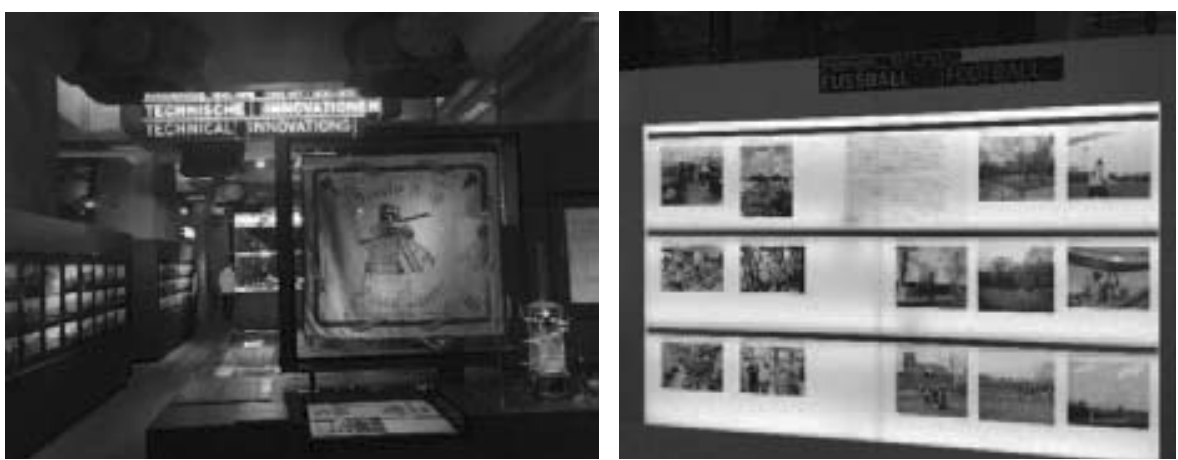

Fig. 12. Depiction of the history of industrial development Source: own research.

In the $\mathrm{M} 3$ exposition, learning and entertainment (edutainment) meaningfully complement each other. An example: two exhibitions "Energy" and "ON / OFF" are dedicated to the topic of energy. The first exhibition tells about the use of energy in human history through the following narrative lines: "Light and heat," "Muscle power," "The transmission of power," "Windpower," "Water power," "Power from coal," "The power engine," and "Industrial society." Although the narrative of the exhibition is historically linear, the exhibition begins with a stand that links the topic of energy to the everyday life of a modern human. The stand exhibits various, immediately recognizable objects, such as a cup of coffee that provides short-term energy, a postcard written by someone on vacation that illustrates the process of energy recovery in human life, etc. They are exhibited next to items that provide new information, such as a small bottle containing oil or a model of Stockholm train station illustrating how heat energy emitted by people can be used innovatively for heating. Although the stand is dominated by items and explanatory texts, they link the topic of the exhibition to everyday experience and thus enable the engagement in learning. Also, the stand offers interactive entertainment: once the screen captures the temperature of the heat emitted by the visitor's body, the visito$r^{\prime}$ s photo with such information can be sent to a personal e-mail address (see Figure 13). 

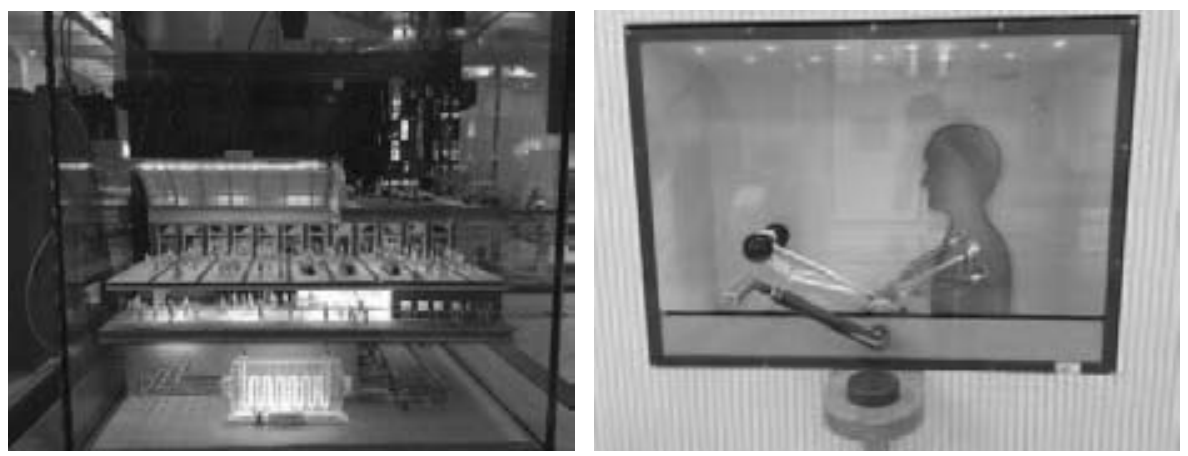

Fig. 13. Training stands at $M 3$

Source: own research.

In museums, it is very difficult to distinguish where learning ends and entertainment begins. In contemporary museums, these activities encourage the visitor to return and once again experience the joy of learning, to emphasize the advantages of experiential learning.

\section{CONCLUSION}

All three researched museums have a strong identity and each of them invites - authentically and in its own way - to participate in the knowledge of the exhibits presented by the museum and in the learning process. M1 presents the national Jewish identity and the plot of the story is associated with Jewish history in Poland. The building of the museum is designed specifically for this museum, given its mission and purpose, which is related to the multi-faceted transmission of history to the visitor, establishing dialogue, and raising tolerance. The museum is unique when it come to the material authenticity: it contains virtually no original artifacts, and originality is created through authentic stories of people, their letters, and personal belongings. A narrative that guides the visitors through historical periods is the most important aspect of this museum. Technological solutions enhance the presentation of the museum expositions, create impressive stories by directing the visitors to become interested and to stay as long as possible in the twists and turns of plots and the search for truth. Innovative technological solutions do not only encourage reading or watching but also touching, smelling, "jumping" through the sounds of music, and listening to authentic stories and sounds. Meanwhile, M2 presents the regional context and highlights the location and experiences faced and gone through in this location. There is a lot of materiality in the museum because the collected exhibits tell about the rich and long history of this region. There is a strong historical narrative, but timeline features can also be noticed. This museum invites visitors to travel through historical periods and topics. Innovative technological solutions make the stories of the exhibition more intense and help visitors to understand 
the life and industrial growth of this region through the depiction of ordinary life. The M3 was also built based on very clear objectives, which are associated with telling the story of technological progress, experiential learning and experimentation, and activating critical thinking. A strong relationship with the visitor is formed in the museum through active and engaging tasks and activities. Lots of authentic items and visual solutions presenting progress can be seen in the museum. Again, exhibits of natural sizes, such as a steam locomotive, can be discovered in this museum. In addition to storytelling, the museum presents the opportunity to try, construct, or analyze the exhibits. Common innovative solutions that invite visitors to actively engage in activities and get to know can also be found in these museums. These solutions include an interactive table/board, sounds of music and their creation, and listening to and reading the stories of authentic heroes. At M2, a story is told by each person on a TV-like stand, where a person can be seen and his or her authentic story is told. Finally, the M3 offers a stand with a presentation of a person, a presentation of his or her work and activities, and a brief biography and virtual introduction.

It is also important to emphasize that all three museums have abandoned the traditional presentation of the exposition in a detailed linear time. Instead, the presentation of a story or topic is based on the time, where Kairos time often intervenes, and the concept of Kairos versus Cronos can be felt. When the visitors are invited to stop and enjoy, when time seems to no longer exist, emotions and experience become important. When the visitors enjoy the sounds of a room, they listen to the sounds of the countryside or try to smell the city park. This is stagnant time, existential time, aesthetic time, sublime - an intense feeling of horror and grandeur, especially in the M1 (the Holocaust). But it can also be a simple pleasure, as in a village (M1) or city (M2), buzzling with the talk of women, children playing, etc. In terms of timeline, it is important how museums construct a sense of time; the time that is subjectively perceived by the visitor is some kind of logic that takes place in a way of movement. A visitor goes and experiences. However, this is achieved through physical movement. The visitor goes from one hall to another, goes through the expositions. Then, the visitor goes through time. It is hard to tell how fast or slow the visitor goes because walking through time does not create a real experience. Stories inviting the visitor to find out their essence, however, are yet more encouraging to learn and experience. There are stops in the M1 when the visitor falls out of historical time and stops for experiences and aesthetic perception.

In terms of storyline, not only historical twists and turns are important, but also the actors, their actions, the setting which is depicted, and the manner of the depiction. The content-related things, the storyline as a content. There is certain logic based on which story is told. And it is not necessarily time. In summary, to this day it is difficult to distinguish between an aesthetic sense and learning, cognition. However, an authentic presence in a museum and empathy for historical narratives that are related to historical events are the things that encourage the visitors most to stay in that space, to experiment, and to ask questions. 


\section{ACKNOWLEDGMENTS}

This article presents findings of the research project THE DIDACTICAL TECHNOLOGY FOR THE DEVELOPMENT OF NUCLEAR EDUCATIONAL TOURISM IN THE IGNALINA NUCLEAR POWER PLANT (INPP) REGION (EDUATOM). This research is funded by the European Regional Development Fund according to the supported activity RESEARCH PROJECTS IMPLEMENTED BY WORLD-CLASS RESEARCHER GROUPS under Measure No. 01.2.2-LMT-K-718 grant (No. 01.2.2-LMT-K-718-01-0084/232).

\section{REFERENCES}

[1] Badalotti, E., De Biase, L., \& Greenaway, P. (2011). The Future Museum. Procedia Computer Science, 7. 114-116.

[2] Barclay, K. (2020). Family, memory and emotion in the museum. Emotion, Space and Society, 35. 100679.

[3] Baxter, P. \& Jack, S. (2008). Qualitative Case Study Methodology: Study Design and Implementation for Novice Researchers. The Qualitative Report, 13(4), 544-559.

[4] Dierking, L. D. \& Falk, J. H. (2005). Using the Contextual Model of Learning to Understand Visitor Learning from a Science Center Exhibition. Science learning in everyday life. 774-778.

[5] Gao, B., Wan, Q., Chang, T., \& Huang, R. (2019). A framework of learning activity design for flow experience in a smart learning environment. In Foundations and trends in smart learning. Springer, Singapore. 5-14.

[6] Hannam, K., \& Ryan, E. (2019). Time, authenticity and photographic storytelling in The Museum of Innocence. Journal of Heritage Tourism, 14(5-6), 436-447.

[7] Heutte, J., Fenouillet, F., Kaplan, J., Martin-Krumm, C., \& Bachelet, R. (2016). The EduFlow model: A contribution toward the study of optimal learning environments. In Flow experience. Springer, Cham. 127-143.

[8] Hom, A. R. (2018). Silent Order: The Temporal Turn in Critical International Relations, Millennium: Journal of International Studies 2018, 46(3), 303-330.

[9] Hwang, G. J. (2014). Definition, framework, and research issues of smart learning environments-a context-aware ubiquitous learning perspective. Smart Learning Environments, 1(1), $1-14$.

[10] Kiili, K. (2005). Content creation challenges and flow experience in educational games: The IT-Emperor case. The Internet and higher education, 8(3), 183-198.

[11] Kirshenblatt-Gimblett, B. (2015). Inside the Museum: Curating between hope and despair: POLIN Museum of the History of Polish Jews. East European Jewish Affairs, 45(2-3), 215-235.

[12] Korzun, D., Varfolomeyev, A., Yalovitsyna, S., \& Volokhova, V. (2017). Semantic infrastructure of a smart museum: toward making cultural heritage knowledge usable and creatable by visitors and professionals. Personal and Ubiquitous Computing, 21(2), 345-354.

[13] Lubar, S. (2013). Timelines in Exhibitions. Curator the Museum Journal, 56(2), 169-188.

[14] Metcalfe, A. (2006). It Was the Right Time to Do It: Moving House, the Life Course and Kairos, Mobilities, 1(2), 243-260.

[15] Palombini, A. (2017). Storytelling and telling history. Towards a grammar of narratives for Cultural Heritage dissemination in the Digital Era. Journal of Cultural Heritage, 24. 134-139.

[16] Pranskuniene, R. (2013). "Submerging interactivity" in museum education: grounded theory. Doctoral dissertation, Klaipeda University.

[17] Sabljić, J., \& Oswald, T. V. (2013). Genre differentiation in A guided Tour through the Museum of Communism by Slavenka Drakulić. Journal of Education, Culture and Society, 4(1), 243-256.

[18] Tim, Y., Ouyang, T., \& Zeng, D. (2020). Back to the future: Actualizing technology affordances to transform Emperor Qin's terracotta warriors Museum. Information \& Management, 103271. 
Journal of Education Culture and Society No. 2_2020

[19] Trunfio, M., \& Campana, S. (2020). A visitors' experience model for mixed reality in the museum. Current Issues in Tourism, 23(9), 1053-1058.

[20] Wong, A., \& Chong, S. (2018). Modeling adult learners' online engagement behavior: proxy measures and its application. Journal of Computers in Education, 5(4), 463-479.

[21] Yin, R. K. (2009). Case study research: Design and methods. Thousand Oaks, CA: Sage. 